\title{
Relationship between Students' Satisfactions of Academic Advising and Students' Success
}

\author{
${ }^{1}$ Hanaa Azmi Saad, ${ }^{2}$ Shaimaa Mohamed Elhadary, ${ }^{3}$ Ghada Hemdan Hamed \\ ${ }^{1}$ Lecturer of Nursing Administration, Faculty of Nursing Modern University for Technology and Information, \\ ${ }^{2}$ Lecturer of Medical Surgical Nursing, Faculty of Nursing, Cairo University \\ ${ }^{3}$ Lecturer of Maternity and Neonatal Health Nursing, Faculty of Nursing Modern University for Technology and \\ Information
}

\begin{abstract}
Academic advising is one of the crucial components for enhancing students' satisfaction and success, many colleges and universities have extended academic support services and programmatic interventions which in turn contribute to affect students' academic success. Aim: Study aimed to investigate the relationship between student satisfaction of academic advising, and students' success. Design: A Descriptive correlation research design was utilized in this study. Setting: The study was carried out at faculty of nursing affiliated to private university at Cairo. Sample:A convenience sample of 230 adult nursing students was included in the present study. Tool:Two tools were used. (1) Self-Administered Questionnaire Tool to assess data related to students personal characteristics, in addition to assess type of academic advising relationship, frequency of academic advising sessions, timing of sessions and students' GPA. (2) Students' Academic Advising Inventory to measure students' satisfaction with academic advising process. Results: there was a highly statistically significant positive correlation between students' satisfaction and their highly satisfying activities during academic advising session; while, highly statistical significant negative correlation was found between students' satisfaction and their study year, GPA and frequency of academic advising session. Conclusion: students' satisfaction of academic advising was negatively related to and students' success. Recommendation: Fostering the role of academic advising in institutions to better student satisfaction and success.
\end{abstract}

Keywords: Students' Satisfactions, Academic Advising, Student Success

\section{Introduction}

\{1] EMPHASIZED THAT THE IDEA OF ACADEMIC ADVISING ORIGINATED IN EARLY AMERICAN COLLEGES AND UNIVERSITIES AS A METHOD FOR BRIDGING THE GROWING DISTANCE BETWEEN FACULTY AND STUDENTS. [2] MENTIONED THAT, THE ROLE OF FACULTY MEMBERS IN RELATION TO THE ACADEMIC PROCESS IS TO COACH, GUIDE, INSTRUCT, TEACH AND SUPPORT STUDENTS IN AN EFFECTIVE WAY TO ACHIEVE EDUCATIONAL OBJECTIVE.

One of the important roles and responsibilities of faculty members in addition to teaching students is providing them with appropriate academic advising. If it is done well, it can help to solve the students' problems and prevent their academic failure. Students expect that the faculty members as a coordinators have sufficient knowledge and information about the curriculum, educational issues, and personal, medical and advisory services[3]. [4]defined academic advising as "developmental process which assists students in the clarification of their life/career goals and in the development of educational plans for the realization of these goals. It is a decision-making process by which students realize their maximum educational potential through communication and information exchanges with the advisor; it is ongoing, multifaceted responsibility of both student and advisor".

Academic advising plays a vital role to students' academic satisfaction and success by guiding them throughout their academic years and by providing them with professional advice and assets to enhance student learning and advancement. There is evidence that how necessary this relationship is to the students' success. "When viewed as an educational process and done well, academic advising plays a pivotal role in connecting students with learning opportunities to foster and support their engagement, success, and the attainment of key learning outcomes" [5].

It was mentioned that academic advising provides the opportunity for the faculty and/or staff members to exchange information designed to help students achieve their educational and career goals in the most efficient, cost-effective manner possible. Students' expectations of the advisee's role in maintaining a successful advisor-advisee relationship focused on communication skills and fulfilling expectations [6].

It was stated that there are different relationships of academic advising such as developmental and prescriptive. Developmental advising which involve students-advisor relationship in a holistic approach; it provides students an opportunity to learn about themselves, and coach them how to be self-sufficient. It is an 
interactive relationship to help students develop and practice planning problem-solving, decisions and critical thinking skills [7].

The prescriptive relationship offers less choice for students to have autonomy all over their academic process. This model offers standard procedures for all students that need much structure, it can sometimes be helpful to students that need to be reminded to read the assignment and attend lectures, look for a mentoring relationship, or engage themselves in an extracurricular activity. When the prescriptive model is in implementation, the student may be viewed as being undeveloped, inexperienced, negligent, in need of strict monitoring, and incompetent in decision-making skills [8] and [9] .

It is emphasized the importance role of faculty-student relationship through indicating that satisfaction with academic advising and satisfaction with faculty support system significantly influenced overall students' satisfaction with the college atmosphere; this, in turn, contributed to student desires to complete postgraduate degrees and positively develop his professional career[10].

Now a day, many researchers investigate the students' opinion about academic advising.[11] surveyed 611 undergraduate students to investigate the relationship between academic advising and students' success or academic performance, the results revealed that academic advising can significantly impact all aspects of a student's academic experience, ranging from advancement of self-efficiency to practical applications of study skills. [12] and [7] notes that effective advisors must appraise each definite student in terms of his needs, interests, skills goals, abilities and adapt their approach to address them properly. Therefore, students who are satisfied with the advising role can increase the probability to be satisfied with their education process because students know that they are on the right track and therefore do not feel lost. The advising process as well can help students to identify personal strengths and interests related to their educational and career goals. This knowledge may inform students' selection and pursuit of extra-curricular activities that enhance their college experience.

\subsection{Significance of the Problem:}

Academic advising plays a crucial role in students' academic success and institutional satisfaction. Traditionally, measurement of advising outcomes focused on student satisfaction with advising process rather than on student success. Although student satisfaction is important in evaluating the efficacy of advising efforts, it requires significantly to measure specific outcomes that can be associated with student achievement. Thus, investigating the relationship between advising and student success can reveal how it helps students develop the knowledge and skills necessary for accomplishment. From that prospect, further research is needed to identify the elements of academic advising that contribute to student success. Therefore, the current study is conducted to investigate the relationship between student satisfaction of academic advising, and students' success.

Operational definition:

Student success: measured by grade of point average (GPA)

\section{AIM OF THE STUDY}

The current study aims to investigate the relationship between students' satisfaction of academic advising, and students' success.

\section{Material and Methods}

With this in mind the following research question were postulated:

$\mathrm{Q}_{1}$ : What is the relationship between students' satisfaction of academic advising and students' students' success?

$\mathrm{Q}_{2}$ : What are the highly students' satisfying activities of academic advising process?

$\mathrm{Q}_{3}$ : What are the lowest students' satisfying activities of academic advising process?

\subsection{Design}

Descriptive correlation research design was utilized in this study. Correlation designs are used to examine if changes in one or more variable are related to changes in another variable(s). This is referred to as co-variance. Correlations analyze direction, degree, magnitude, and strength of the relationships or associations[13].So, correlation design is most appropriate for this study, because it allows two variables to show if they have a positive or negative relationship between students' satisfaction of academic advising and their success.

\subsection{Setting}

The current study was conducted in a faculty of nursing affiliated to private university at Cairo. 


\subsection{Sample:}

A convenience sample of 230 adult nursing students was included in the present study. The students enrolled in the study were representative from all the study years. They are Egyptian, foreigners \& willing to participate in the study.

\subsection{DataCollection Tool:}

The researchers used two tools to gather data pertinent to fulfill the study aim as follows:

Self-Administered Questionnaire Tool:

This tool was developed by the researchers in English language based on literature review and instruments related to the study scope. It concerned with data related to students' personal characteristics as gender, age, nationality and study year. In addition to type of academic advising relationship ,frequency, time of academic advising session and its timing. It includes also students' GPA which was recorded by the researchers from the student's affairs department.

Students' Academic Advising Inventory: This tool was adopted from [14].It is a self-reported questionnaire to measure student satisfaction with academic advising process. It covers the following three areas: (1) nature of advising relationship, which consists of two questions, (2) activities that takes place during advising session, it consisted of twelve questions and (3) student' satisfaction of academic advising, it consisted of ten questions.

\section{Scoring System:}

All items was rated on likert scale according to students' response for each item, from 1 to 3 where 3 indicate high satisfaction, 2 indicate average satisfaction \& 1 indicates low satisfaction.

\subsection{Pilot study}

Pilot study was carried out on $10 \%$ of first year nursing students at Faculty of Nursing, to test clarity and feasibility of items to subjects and to test needed time for filling the tools. Some items required clarifications from researchers with no modification needed. Participants who shared in the pilot study were not included in the study sample

\subsection{Procedure for data collection:}

Foremost, researchers obtained an official permission from the authoritative persons of the faculty of nursing to conduct the current study; as well as preparation of the study tools. The researchers arranged time to meet students and give full description about the aim of the study and written informed consents were collected from students who agreed to participate in the study. Data collection spent time of three months started from January, 2017 to April 2017 to assess the role of academic advisor in achieving student satisfaction and students' academic success using self-administered questionnaire. Time needed for completing the tool was 30 minutes. After that, the researchers started data collection of the second tool which related to students' academic advising format to measure student satisfaction with academic advising process. The students were invited to fill out the data collection tools. All questions were answered and explanations were given accordingly. Then students' grade point average (GPA) were obtained from authoritative personnel and recorded respectively.

\subsection{Statistical analysis:}

Data was entered and analyzed using Statistical Package for Social Science software (SPSS version 22); Data related descriptive statistics were summarized using mean as an average, standard deviation as a measure of dispersion of result around the mean. While for the inferential results, correlation test was used.The alpha level of .05 was utilized for all tests of significance. The internal consistency of all tools was conducted by Cronbach alpha.

\subsection{Ethical Considerations}

The study protocol was approved by authoritative staff of faculty of nursing, to conduct the current study. Students were assured to express his/her opinion regarding academic advising process while confidentiality and anonymity were applied through assigning a code number for each student instead of names to protect their privacy; students were informed that participation at the study was completely voluntarily and they had the right to withdraw at any time with no effect on their grades and evaluation. The students were assured that data are confidential and used only for research purposes.

\section{Results}

Results of the study are presented in two major parts; the first part is descriptive statistics that included the personal characteristics of the study sample, students' highly and low satisfying activities that took place 
during academic advising sessions. The second one is inferential statistics that presents the relationships between the study variables; students' satisfaction, students' success with the academic advising.

Table (1) illustrated that $(43.5 \%)$ of the study participants were male whereas $(56.5 \%)$ were female. $(32.6 \%)$ of the studied participants were in first year of study whereas $(26.1 \%)$ of them were in second, $(21.7 \%)$ were in third year of study and $(19.6 \%)$ of them were in fourth year of study. It was found that $(78.4 \%)$ of the study participants are Egyptian whereas $(21.7 \%)$ are foreigners.

Table (2) revealed that $(60.9 \%)$ of the study participants reported a prescriptive style of academic advising, meanwhile, (39.1\%) reported a developmental style. Regarding time allotted for advising, $(8.7 \%)$ of the study participants spent less than 15 minutes, (73.3\%) spent 15 - less than 30 minutes, (17.4\%) spent $30-$ less than 45 minutes during academic advising session with a mean + SD of 2.08+ 0.50.Related to GPA, $(54.3 \%)$ were $>2$ and $(45.7 \%)$ were $<2$.

Figure (1) illustrated that $(60 \%, 56 \%, 50 \%$ and $49 \%$ respectively) of the study participants had highly satisfaction with issues related to GPA, dropping or adding courses, transfer credit and financial aids as an activities that take places during advising sessions.

Figure (2) illustrated that $(70 \%, 66 \%, 57 \%$ and $55 \%$ respectively) of the study participants had low satisfaction with issues related to academic problems, concerns related to professors, faculty academic bylaws and evaluating academic progress as an activities that take places during advising sessions.

Table (3) demonstrated a highly statistical significant negative correlation was detected between students' satisfaction and their GPA $(\mathrm{r}=-0.79$ at $\mathrm{p}=.000)$.

Table (4) revealed a highly statistically significant positive correlation was detected between students' satisfaction and their highly satisfying activities during academic advising session $(r=0.86$ at $\mathrm{p}=.000)$.

Table (5) illustrated a highly statistical significant negative correlation was detected between students' satisfaction and their study year $(r=-0.867$ at $\mathrm{p}=.000)$.

Table (6) demonstrated a highly statistical significant negative correlation was detected between students' satisfaction and the frequency of academic advising session. $(r=-0.577$ at $\mathrm{p}=.000)$.

Table (1): Frequency and percentage distribution of the study personal characteristics $(n=230)$.

\begin{tabular}{|l|l|l|}
\hline Variables & No. & Percentage \% \\
\hline Study Year: & & \\
\hline First & 75 & 32.6 \\
\hline Second & 60 & 26.1 \\
\hline Third & 50 & 21.7 \\
\hline Fourth & 45 & 19.6 \\
\hline Nationality: & & \\
\hline Egyptian & 180 & 78.3 \\
\hline Foreigner & 50 & 21.7 \\
\hline Gender: & & \\
\hline Male & 100 & 43.5 \\
\hline female & 130 & 56.5 \\
\hline
\end{tabular}

Table (2):Frequency and percentage distribution of the study participants' as regards to nature of academic advising relationship, time, frequency of academic advising sessions and Students' GPA (n=230).

\begin{tabular}{|c|c|c|}
\hline Variables & No. & Percentage \% \\
\hline \multicolumn{3}{|l|}{ Nature of academic advising relationship: } \\
\hline $\begin{array}{l}\text { Developmental style considering student's } \\
\text { interest }\end{array}$ & 90 & 39.1 \\
\hline Prescriptive style based on authority & 140 & 60.9 \\
\hline \multicolumn{3}{|l|}{ Time: } \\
\hline$<15$ minutes & 20 & 8.7 \\
\hline $15-$ & 170 & 73.3 \\
\hline 30- & 40 & 17.4 \\
\hline 45-60 minutes & $\mathbf{0}$ & $\mathbf{0}$ \\
\hline & \multicolumn{2}{|c|}{ Mean + SD $\quad 2.08+0.50$} \\
\hline \multicolumn{3}{|l|}{ Frequency of academic advising session: } \\
\hline One time during registration & 170 & 73.9 \\
\hline $\begin{array}{l}\text { Two times during registration } \& \text { when } \\
\text { facing problems }\end{array}$ & 41 & $\mathbf{1 7 . 8}$ \\
\hline \multirow[t]{2}{*}{$\begin{array}{l}\text { Three times during registration, when } \\
\text { facing problems and for consultation }\end{array}$} & 19 & 8.3 \\
\hline & \multicolumn{2}{|c|}{ Mean + SD 1.34+ 0.62} \\
\hline \multicolumn{3}{|l|}{ Grade point average (GPA) } \\
\hline$<2$ & 105 & 45.7 \\
\hline \multirow[t]{2}{*}{$<2$} & 125 & 54.3 \\
\hline & \multicolumn{2}{|c|}{ Mean + SD 2.33+ 0.88} \\
\hline
\end{tabular}


Figure (1): Rating of percentage distribution of highly satisfying activities that take places during advising sessions as reported by the study participants' $(\mathrm{n}=230)$.

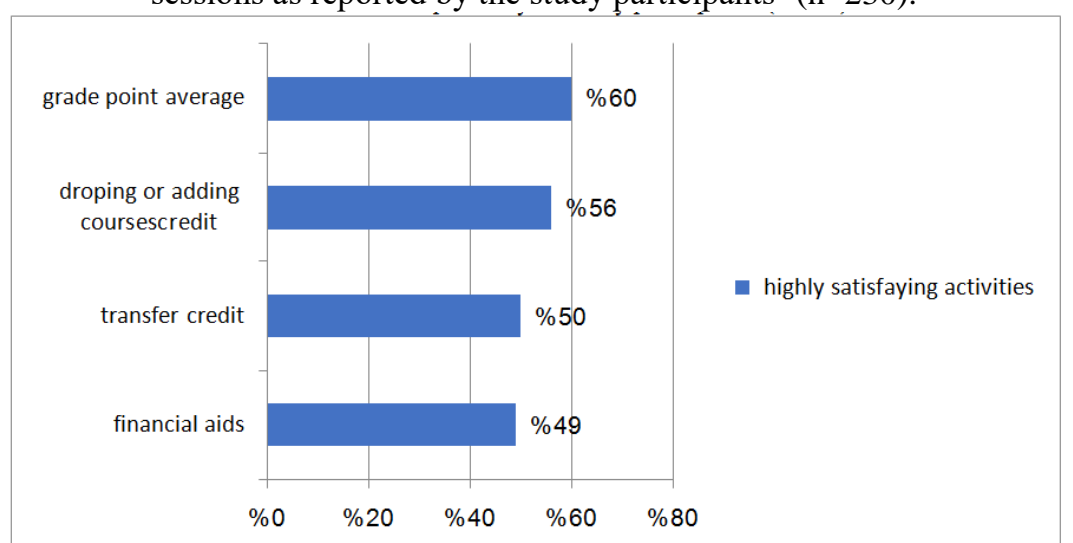

Figure (2): Rating of percentage distribution of low satisfying activities that take places during advising sessions as reported by the study participants' $(\mathrm{n}=230)$.

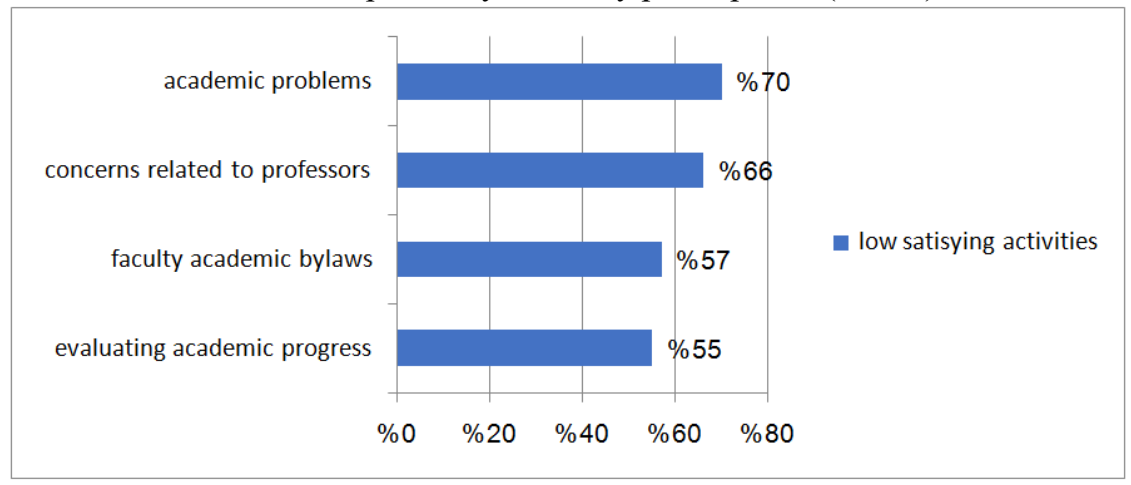

Table (3):Correlation between mean scores of students' satisfaction of academic advising process and mean of grade point average (GPA) $(\mathrm{n}=230)$.

\begin{tabular}{|l|c|c|c|}
\hline \multicolumn{1}{|c|}{ Variables } & Mean + SD & F value & p-value \\
\hline Students' satisfaction scores & $\mathbf{1 . 7 4 + 0 . 7 3}$ & $\mathbf{- 0 . 7 3 0}$ & $\mathbf{0 . 0 0 0}$ \\
\hline Students' success (GPA ) & $\mathbf{2 . 3 3 + 0 . 8 8}$ & & \\
\hline Type of correlation & negative & \\
\hline
\end{tabular}

Table (4): Correlation between mean scores of students' satisfaction of academic advising process and highly satisfying activities during academic advising session $(\mathrm{n}=230)$

\begin{tabular}{|l|c|c|c|}
\hline \multicolumn{1}{|c|}{ Variables } & Mean + SD & F value & p-value \\
\hline Students' satisfaction scores & $1.74+0.73$ & 0.863 & 0.000 \\
\hline $\begin{array}{l}\text { Academic advising } \\
\text { activities }\end{array}$ & $1.91+0.71$ & & \\
\hline Type of correlation & positive & \\
\hline
\end{tabular}

Table (5): Correlation between students' satisfaction of academic process and study year ( $\mathrm{n}=230)$

\begin{tabular}{|l|c|c|c|}
\hline \multicolumn{1}{|c|}{ Variables } & Mean + SD & F value & p-value \\
\hline Students' satisfaction & $1.74+0.73$ & -0.86 & 0.000 \\
\hline Study year & $2.28+1.11$ & & \\
\hline Type of correlation & negative & \\
\hline
\end{tabular}

Table (6): Correlation between mean scores of students' satisfaction of academic process and frequency of academic advising sessions $(\mathrm{n}=230)$

\begin{tabular}{|c|c|c|c|}
\hline Variables & Mean + SD & F value & p-value \\
\hline
\end{tabular}


Relationship between Students' Satisfactions of Academic Advising and Students' Success

\begin{tabular}{|c|c|c|c|}
\hline Students' satisfaction & $1.74+0.73$ & \multirow[t]{2}{*}{-0.557} & \multirow[t]{2}{*}{0.000} \\
\hline $\begin{array}{l}\text { Frequency of academic } \\
\text { advising sessions }\end{array}$ & $1.34+0.62$ & & \\
\hline
\end{tabular}

\section{Discussion}

This study intends to investigate the relationship between academic advising, student satisfaction and students' success. Regarding the students' personal data, the findings revealed that the most of the studied group registration was in first year then the second, third and fourth respectively, more than half of them were female, more than three fourth was Egyptian in addition to the highest percentage of the studied sample was from the first academic year. This may be due to students' conviction about the nursing profession as a future career that can close the nursing employment gap.

Concerning frequency distribution of the study participants' as regards to nature of academic advising relationship, the finding revealed that two third of them preferred prescriptive style based on authority ,the researchers viewed that in these days students are irresponsible and need more argument to choose the proper choices in addition to students' need to tell them what to do, when, why and how. This is against to [15]who mentioned in their study that all advisors reported that they preferred developmental advising, since this style are shared process in which the advisor and student have equal authority.

Regarding time and frequency of academic advising sessions, less than three fourth of students entirely that academic advisor meet advisee only one time during registration, for the duration of 15 to 30 minutes. The researchers viewed that meeting advisee once per semester with this limited time isn't enough to guide, instruct and solve many academic problems faced the students. This is in agreement with [16] who emphasized on the role of academic advising which is the delivery of advice as well as students' assistance concerning the academic, personal and career development, in addition to students who attended two faculty advising sessions which was a statistically significant higher than students who did not attend the advising sessions, while in other study conducted by [17] who reported that although student satisfaction with undergraduate education was high, satisfaction with advising was much lower. [18]tested students' immediate learning successes from advising sessions and found that students who contacted advisors often have more clear educational plan and better known resources.

Relating to scholastic acquirements, slightly more than half of study sample got more than two in GPA, when trying to analyze the outcome and correlate it with academic sessions, it was found that the increases in GPA had no relation with the role or advising activity during the session, but due to the advisors' notification about the importance of passing the proposed GPA for required registration or graduation. Academic advisor impact student satisfaction through his guidance and support about courses selection. The researchers viewed that if academic advisor recognize well his role, he can help students navigate academic rules and regulations, help students schedule their courses. This is supported by [11], who examined the association between academic advising and grade point average, they did not observe a statistically significant correlation. On the other side [19]point out the impact of students' advising who attended two or more faculty advising sessions had a grade point average (GPA of 2.0 or higher).

Related to the rating percentage distribution of low satisfying activities that take places during advising sessions, the study findings illustrated that more than two third of the study sample had low satisfaction with issues related to academic problems faced students and students' professors relationship, in addition to the unfamiliarity of faculty academic bylaws, this could be explained that when the students aren't aware of the rules and regulation, they will develop a sense of rejection and confusion within the institution and thus in turn will affect their scholastic achievement. This is in congruence with [20] as well [21]who emphasis on academic advisor role/duty in clarifying and solving such problems and concluded that advisors who did not have full responsibility for their professional duties as a result of knowledge deficit and lack of training skills have a negative effect on the institution, therefore, advising becomes more difficult[22].

\section{Conclusion}

The study revealed that students' satisfaction of academic advising was negatively related to students' success. Faculty members should strive to put student success at the highest priority during academic advising process. Academic advising should be the core of faculty members' efforts to educate students and help the students to achieve higher level of success.

\section{Recommendation:}

1. Disseminate the finding results to more investigation related to the effectiveness between advising services and student success/satisfaction.

2. Provide conductive culture for advising to facilitate the students'-advisors relationship. 
3. Establish an awareness program for newly academic advisors in the beginning of each year to exchange experiences and find solutions to some of the previous difficult problems.

4. Fostering the role of academic advising in institutions to better student satisfaction and success.

5. Investigate the relationship between advisors and faculty collaboration work to improve the student experience and outcomes.

\section{References}

[1] Barbuto,J.E., Story,J.S.,Fritz,S.M.,\&Schinstock,J.L.(2011).Full range advising: Transforming the advisor-advisee experience.Journal of College Student Department.52(6),656-670.

[2] Sastre, E.A.; Burke, E.E.; Silverstein, E.; Kupperman, A.; Rymer, J.A.; and Davidson, M.A. et al., (2010): Improvements in medical school wellness and career counseling: A comparison of one-on-one advising to an Advisory College Program. Med Teach. 2010;32(10):e429-35

[3] Lotfi, M.; Fazelpur, S., Abuyi, M.; Ghane, B.; and Vatani, J. (2012): To evaluate the role of Advisor teacher in average score of shahed\&Isargar students of shahidsadoughi university of medical science, 2002-2007. EDC journal. 2012; 4(7):54-60. Persian.

[4] Lowenstein, M. (Spring 2009). Advising as teaching. NACADA Journal 29(1), 123-131.

[5] Campbell, S. M., \& Nutt, C. L. (2008). Academic advising in the new global century: Supporting studentengagement and learning outcomes achievement. Peer Review, 10(1), 4-7.

[6] Pargett, K. (2011): The Effects of Academic Advisors on College Student

[7] Hale, M. D., Graham, D. L., Johnson, D. M. (2009). Are students more satisfied with academic advising when there is congruence between current and preferred advising styles? College Student Journal, 43(2).

[8] Crookston, B. B. (2009). A developmental view of academic advising as teaching. NACADA Journal, 29(1), 78-82. doi:10.12930/0271-9517-29.1.78

[9] Robbins, R. (2012). Everything you have always wanted to know about academic advising (well, almost). Journal of College Student Psychotherapy, 26(3), 216- 226. doi:10.1080/87568225.2012.685855

[10] Hawthorne, M. and Young, A. (2010): "First-generation transfer students' perceptions: implications for retention and success", Journal of College Orientation \& Transition, Vol. 17 No. 2, pp. 29-39.

[11] Young-Jones, A.D.; Burt, T. D., Dixon, S.,and Hawthorne, M. J. (2013): Academic Advising: Does it Really Impact Student Success? Quality Assurance in Education, 21(1), 7-19.

[12] .Simpson, S.(2013): Advise Me: Understanding Undergraduate Student Perceptions of Learning inAcademic Advising. Theses and Dissertations Communication. Paper 10. Retrieved fromhttp://uknowledge.uky.edu/comm_etds/10

[13] Burns N, Grove SK. The practice of nursing research: conduct, critique, and utilization. 5th ed. St Louis: Elsevier; 2005

[14] Winston, R. B., Jr., \&Sandor, J. A. (1984). Developmental academic advising: What do students want? National Academic Advising Association [NACADA] Journal, 4(1), 5-13.

[15] Brown, J. and Gladys, P. (2012): "Advising Style Perceptions and Preferences of Students and Advisors". Dissertations. Paper 26. http://digitalcommons.wku.edu/diss/26. Western Kentucky University, pat.jordan@wku.edu.

[16] Nor, A. S. M., Zaini, R. M., \&Zahid, S. M. (2013). Shortage of accountants: Does mentoring helps to increase the number? International Conference on Social Science Research, ICSSR 2013, 4-5 June 2013, Penang, MALAYSIA

[17] Sutton, K. L., \&Sankar, C. S. (2011). Student satisfaction with information provided by academic advisors. Journal OfSTEMEducation: Innovations And Research, 12(7-8), 71-85. Retrieved from ERIC.

[18] Smith, C. L., \& Allen, J. M. (2014). Does contact with advisors predict judgments and attitudes consistent with student success? A multi-institutional study. NACADA Journal, 34(1), 50-63.

[19] Williamson, L. L., Goosen, R. A., \& Gonzalez, G. F. (2014). Faculty advising to support student learning. Journal of Developmental Education, 38(1), 20-24. Retrieved from Education Full Text.

[20] Behrens, S. (2013). Is the office hour obsolete? Research \& Teaching in Developmental Education, 29(2), 30-37. Retrieved from http://www.nyclsa.org/index.html.

[21] Dichaba, M. M. (2013). Adult basic education teachers' experiences about the cascade model of training: An appreciative inquiry. International Journal of Educational Science, 5(1), 29-38. Retrieved from http://krepublishers.com/02- Journals/IJES/IJES-05-0000-13-Web/IJES-05-0-000-13-Contents/IJES-05-0- 000-13-Contents.htm.

[22] Kim, Y. K., \& Sax, L. J. (2014). The effects of student-faculty interactions on academic self-concept: Does academic major matter? Research in Higher Education, 55(8), 780-809. doi:10.1007/s11162-014-9335. 